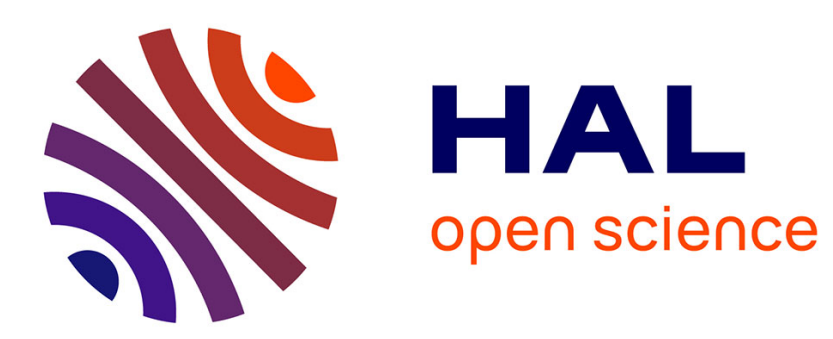

\title{
Design and test of a friction damper to reduce engine vibrations on a space launcher
}

Denis Brizard, Sébastien Besset, Louis Jezequel, Bernard Troclet

\section{To cite this version:}

Denis Brizard, Sébastien Besset, Louis Jezequel, Bernard Troclet. Design and test of a friction damper to reduce engine vibrations on a space launcher. Archive of Applied Mechanics, 2012, 83 (5), pp 799815. hal-00989368

\section{HAL Id: hal-00989368 https://hal.science/hal-00989368}

Submitted on 12 May 2014

HAL is a multi-disciplinary open access archive for the deposit and dissemination of scientific research documents, whether they are published or not. The documents may come from teaching and research institutions in France or abroad, or from public or private research centers.
L'archive ouverte pluridisciplinaire HAL, est destinée au dépôt et à la diffusion de documents scientifiques de niveau recherche, publiés ou non, émanant des établissements d'enseignement et de recherche français ou étrangers, des laboratoires publics ou privés. 


\title{
Design and test of a friction damper to reduce engine vibrations on a space launcher
}

Received: date / Accepted: date

\begin{abstract}
Space launchers are submitted to complex vibration environments and this can impact the payload it is carrying. Ensuring the protection of the payload therefore requires the addition of a secondary system. In this paper, a rapid design method for the dimensioning of a friction damper is developed, based on the equivalent energy dissipation with that of a viscous damper. A friction damper is designed and a prototype is built. The friction damper is first characterised alone and it is then mounted inside a scale model of a launcher last stage. The friction damper is adequately modelled by a spring in series with a friction element. The damper prototype proves to efficiently damp the rocket engine vibrations and the design method used for dimensioning the friction damper gives a good approximation for the optimal sliding force of the damper.
\end{abstract}

Keywords Space launcher · Damping · Vibration testing · Friction damper

\section{Nomenclature}

$W_{c}$ dissipated energy per cycle in the viscous damper

$W_{f}$ dissipated energy per cycle in the friction damper

$k_{f}$ stiffness of the friction damper

$F_{g}$ sliding force of the friction damper

$p$ pressure in the hydraulic jack of the friction damper prototype

$f$ excitation frequency

$u_{0}$ excitation amplitude

$F(t)$ temporal signal of the tangential force in the friction damper

D. Brizard

Laboratoire de Tribologie et Dynamique des Systèmes UMR-CNRS 5513

École Centrale de Lyon

36 Avenue Guy de Collongue

69134 Ecully Cedex, France

Tel.: +33472186464

E-mail: denis.brizard@ec-lyon.fr

S. Besset

Laboratoire de Tribologie et Dynamique des Systèmes UMR-CNRS 5513

E-mail: sebastien.besset@ec-lyon.fr

L. Jézéquel

Laboratoire de Tribologie et Dynamique des Systèmes UMR-CNRS 5513

E-mail: louis.jezequel@ec-lyon.fr

B. Troclet

EADS Astrium

66, Route de Verneuil

78133 Les Mureaux, France

E-mail: bernard.troclet@astrium.eads.net 
$u(t)$ temporal signal of the relative displacement across the friction damper

$T$ period of the temporal signals (inverse of $f \mathrm{f}$ )

$A$ area of the force-displacement $(F-u)$ curve

$A+$ area of the force-displacement curve above $F=0$

$A$ - area of the force-displacement curve below $F=0$

$F_{n}$ normal force in the friction damper

$F_{g p}$ positive sliding force of the friction damper

$F_{g n}$ negative sliding force of the friction damper

$\mu$ friction coefficient of the brake lining

$A_{\text {trap }}$ area of the absolute value of the force signal $F(t)$

$\tau$ ratio of sliding time to oscillation period of the friction damper

\section{Introduction}

Space launchers undergo complex dynamic excitations through their lifecyle. They undergo various types of excitations, which can be transient, random or harmonic. These excitations are notably generated by pressure oscillations in the rocket engines, gust loads, stage separations and pyrotechnic separations. All these excitations have a low frequency component, which may be transmitted to the payload of the launcher and could damage it. The architecture of the launcher is however fixed at an early stage and is thus difficult to modify. The payload is fixed on the last stage, its protection in the low frequency domain can be improved by the addition of a secondary system whose aim is to damp the vibrations generated or recovered by the rocket engine of the launcher last stage. Indeed, the mass of the engine counts for a great part of the total mass of the launcher last stage and damping its vibration would reduce the vibrations transmitted to the payload.

This paper is part of a larger project on space launcher vibration damping. The numerical part of the project [2] consisted in developing efficient modal reduction methods for describing the behaviour of the launcher stage and being able to take into account of local structural modifications. This was used to determine the location of damping devices in the launcher stage and assess their efficiency. The second part of the project was a bibliographic study for the choice of the technology for the damper. The third part of the project is an experimental part, allowing both to asses the validity of the numerical simulations and acting as a technology demonstrator. A scale model of the launcher last stage is designed and built, along with a dedicated seismic test rig. A friction damper prototype is also designed and built; it is first tested alone before being mounted inside the scale model for damping tests.

The aim of the present work is to develop a methodology for the design of a friction damper and to validate it through experimental tests on a scale model of the launcher last stage. The choice of damping vibrations with a friction damper is driven here by the opportunity to transform it into a semi-active friction damper without changing its design. Active devices are discarded, they require too much onboard energy and would penalize the launcher by adding too much mass; active solutions are also far less robust than semi-active or passive solutions in case of a control system-failure. At last, active systems could bring stability issues and interact with the control system of the launcher's trajectory. This paper therefore focuses on the adaptive friction damper as a first step toward the semi-active damper.

There is a large body of literature devoted to friction damping in forced systems $[3 ; 7]$. Many articles are devoted to friction-induced vibration and squeal, an interesting review is made by Ibrahim $[9 ; 8]$. Friction dampers is however a more recent area.

There is very few literature on friction dampers for aerospace purposes. A friction damper called SARO already exists and has flown on the Ariane 5 space launcher since a few years. This damper is however purely passive, the sliding force is constant and it may not be transformed into a semi-active damper because of its cylindrical conception [15] (metallic washers rub inside a metallic bore); it is also designed for very small displacements under $1 \mathrm{~mm}$. In a review of passive damping devices for aerospace structures, Rittweger [14] evokes a passive friction damper prototype, of the SARO in fact, and some test results are given.

Some interesting friction devices can be found in civil engineering applications, for the protection of buildings against seismic risks. Mualla et al. [13] proposed a new passive friction damper device working with a bracing system between storeys. It is based on the relative 
rotation between plates and friction pad disks and was further studied [4; 10]. Mirtaheri et al. [12] developed a cylindrical friction damper based on the tight fit between a shaft and its bore.

Guglielmino et al. designed an automotive semi-active friction damper $[5 ; 6]$ aiming to replace the classical viscous damper; the damping force is however smaller than what is needed here and the authors encountered some difficulties regarding the semi-active hydraulic pressure for the modulation of the friction force. That is why as a first step we concentrated here on a passive device.

This paper is organized as follow. Section 2 introduces the space launcher stage model and the design method for for the friction damper. Section 3 describes the friction damper prototype and the test results of the prototype alone. In Section 4, numerical simulations of mechanical structures with dry friction are developed to better understand the test results of the stage model equipped with the friction damper in Section 5.

\section{Method for the design of the friction damper}

\subsection{Host structure: space launcher stage model}

A scale model of a space launcher last stage is designed and built (see Figure 1a). It is based on mass specifications, dimension specifications and frequency specifications in order to get energies and frequencies comparable to those of a real launcher. The frequencies of the payload flexion mode and the engine flexion mode are required to be around respectively $15 \mathrm{~Hz}$ and $20 \mathrm{~Hz}$. The whole model is $2.05 \mathrm{~m}$ high, measures $1.2 \mathrm{~m}$ in diameter and weighs $1.58 \mathrm{t}$.

The stage model is mainly composed of an outer shell and an inner shell supporting a ballast which represent the rocket engine (see Figure 1a). On top of the stage, a tray on three small columns holds the payload; these parts represent the attachment and spacing system of the payload. The ballast weighs $800 \mathrm{~kg}$ and the payload $60 \mathrm{~kg}$. The model is made of steel and the inner shell is drilled to match the required stiffness without having a too thin metal sheet. Two points of interest are materialized: they are the locations of accelerometers at the bottom of the engine (B1) and at the bottom of the payload (L1).

The scale model was designed using CAD software Catia and with ANSYS. Once this design was fixed, a simplified mesh was created. This simplified finite elements model is constructed from the geometry and characteristics of the scale model; it uses shell, beam, volume, mass and rigid elements (see Figure 1b). The use of this simplified mesh, along with a Double Modal Synthesis reduction technique [2], allows fast calculation of the response of the structure. This will be useful to design the optimal damping solution for the protection of the payload.

\subsection{Design method}

The architecture of the launcher is fixed at the beginning of the project, the protection of the payload therefore requires the addition of a secondary system to damp the vibrations generated or recovered by the rocket engine. The general idea is to use the engine as a tuned mass damper by adding a dissipative link between the engine and the outer shell $(\bullet \bullet$ on Figure 1b).

In a previous paper [2], a determinantal method was proposed to evaluate the influence of structural modifications on the complex eigenvalues of a structure. This method only requires the response of the structure at the connection points of the structural modification and allows a fast evaluation of the behaviour of the modified structure thanks to a dedicated continuation algorithm. The determinantal method is applied here to determine the optimal viscous damping of the added dissipative link corresponding to the maximal modal damping of the engine mode.

The launcher is equipped with a horizontal link between the engine ( $\bullet$ on Figure $1 \mathrm{~b})$ and the outer shell. This link is composed of a spring in series with a viscous damper (-M- $)$. The influence of both the stiffness $k$ and the damping $c$ of the links is illustrated by Figure 2 ; the blue curves correspond to the evolution, in the complex plane, of the pole of the engine mode with a damping parameter $c$ varying from 0 (initial pole $\times$ ) to $\infty$ (zero $\circ$, corresponding to the blocked frequency) and a fixed stiffness parameter; the red curves correspond to the evolution of the pole with a fixed damping parameter and a stiffness parameter decreasing from $\infty$ to 0 (from left to right on Figure 2). When the stiffness of the link tends toward zero, it amounts to remove the link: that is why the pole tends to return to its initial - unmodified - value. This 


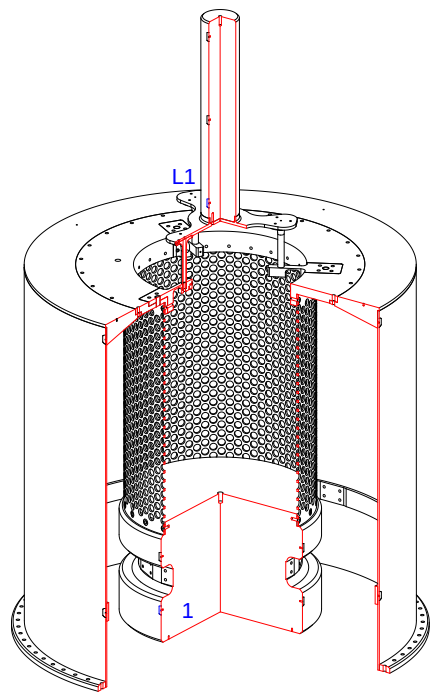

(a)

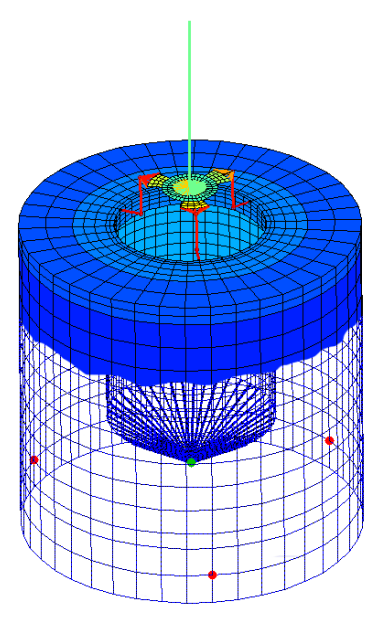

(b)

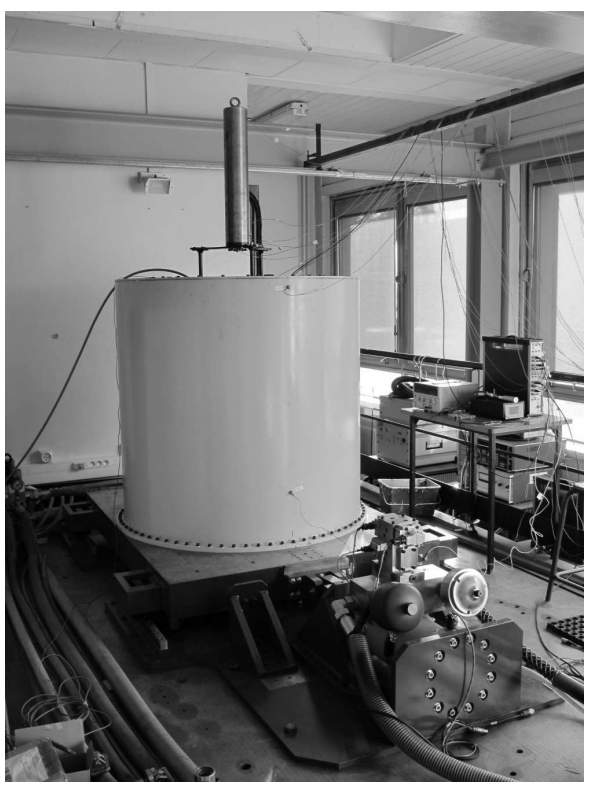

(c)

Fig. 1: Last stage scale model: (a) cross-section view; (b) mesh of the model; and, (c) photography of the scale model clamped on the shaking table

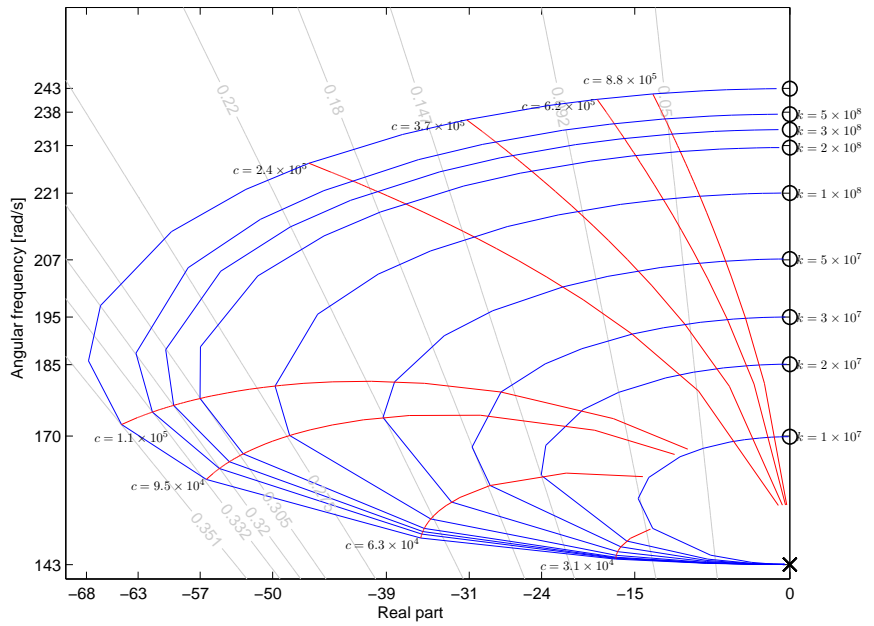

Fig. 2: Evolution in the complex plane of the damped stage second eigenvalue for varying $\mathrm{k}$ and c parameters $(x$ poles, o zeros)

kind of graphic allows to evaluate the sensitivity of the pole to the parameters of the links, which may be crucial at a pre-design stage.

The damping predictions used a viscous damper since it allowed fast calculation for this pre-design stage. The dimensioning of the friction damper is therefore based on the equivalent dissipation of energy with that of the viscous damper used for computing (see Figure 3).

The greatest modal damping is reached for a viscous damping of $c_{\mathrm{eq}}=1.1 \times 10^{5} \mathrm{~N} \mathrm{~s} \mathrm{~m}^{-1}$. Figure 2 shows that even if the link is more supple, down to $1 \times 10^{8} \mathrm{Nm}^{-1}$, $c_{\mathrm{eq}}$ is nearly unchanged. The dissipated energy in a viscous damper of damping $c_{\mathrm{eq}}$ for a periodic imposed displacement of amplitude $U_{0}$ is

$$
W_{c}=\pi c_{e q} \omega U_{0}^{2}
$$




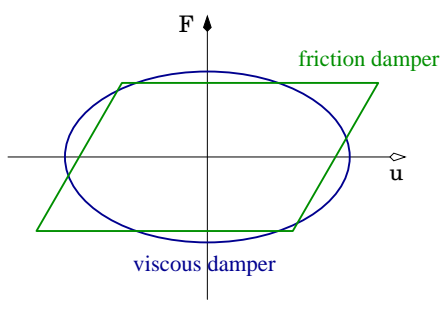

Fig. 3: Comparison of the force-displacement characteristic of a friction damper and of a viscous damper

The friction damper is modelled by a spring of stiffness $k_{f}$ and a friction element with associated sliding force $F_{g}$ (see Figure 5a). The dissipated energy is still the area inside the force-displacement curve

$$
W_{f}=4 F_{g} U_{0}\left(1-\frac{F_{g}}{k_{f} U_{0}}\right)
$$

For the friction damper, the dissipated energy depends on its two intrinsic parameters: the sliding force $F_{g}$; and the damper stiffness $k_{f}$. Decreasing the stiffness for a given sliding force would reduce the dissipated energy ( $U_{0}$ and $\omega$ being unchanged). From the previous equation, the optimal sliding force $F_{g}^{o p t}$ - for which energy dissipation is maximum - is a function of $k_{f}$ and $U_{0}$

$$
F_{g}^{o p t}=\frac{1}{2} k_{f} U_{0}
$$

and the energy dissipation is

$$
W_{f}^{\max }=k_{f} U_{0}^{2}
$$

The friction damper stiffness is deduced from equations 1 and 4 in order to get the same energy dissipation - ie. $W_{f}^{\max }=W_{c}$ - and considering the optimal sliding force $F_{g}=F_{g}^{o p t}$,

$$
k_{f}=\pi c_{\mathrm{eq}} \omega
$$

Which gives, near the resonance frequency of $20 \mathrm{~Hz}$

$$
k_{f}=\pi \times 1.1 \times 10^{5} \mathrm{Ns} \mathrm{m}^{-1} \times 2 \pi 20 \mathrm{~s}^{-1}=4.3 \times 10^{7} \mathrm{~N} \mathrm{~m}^{-1}
$$

The relative displacement $u_{0}$ is supposed to be around $1 \mathrm{~mm}$ (acceleration of the engine of $3 \mathrm{~g}$ at $30 \mathrm{~Hz}$ ), which gives a sliding force $F_{g}^{o p t}$ of $2 \times 10^{4} \mathrm{~N}$. This value was used for the dimensioning of the friction damper.

The aim of this study is to assess the validity of the equivalent dissipation approach through experimental tests, assess the feasibility of a friction damper prototype and test its real/effective performances for reducing the payload vibrations .

Next section introduces the friction damper prototype - with adjustable sliding force that was designed and built. The organic test procedure is then explained and eventually the behaviour of the damper is characterised.

\section{Friction damper behaviour}

\subsection{Friction damper prototype}

The schematic diagram of principle of the friction damper prototype is illustrated by Figure 4a, a cross-section view is given in Figure $4 \mathrm{~b}$. The friction damper is composed of a slider equipped on both sides with brake linings (Flertex 377 material); the friction slider is squeezed between the frame of the device and the square piston activated by the piston stem of the hydraulic jack. The friction damper can be attached to the host structure by two ball joints, one bound to the slider and the second one to the frame. Lastly, the friction slider is guided on its two remaining sides by PTFE plates. Note that the hydraulic jack could be shorter since no stroke is needed, this is indeed an off the shelf component. The prototype weights $30 \mathrm{~kg}$, which is 


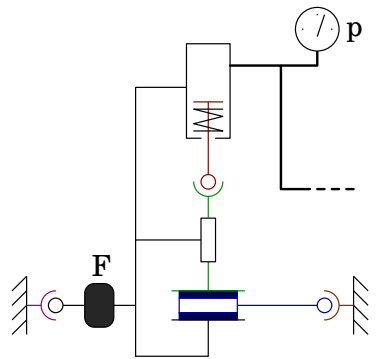

(a)

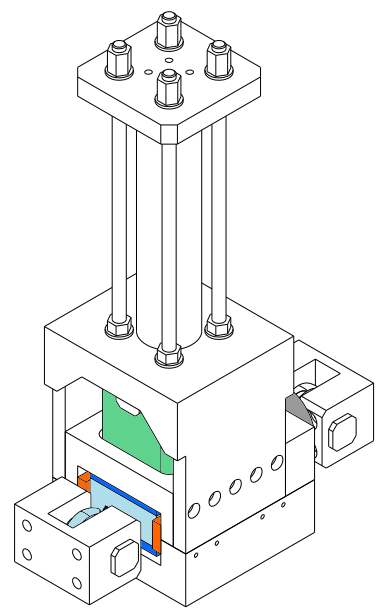

(c)

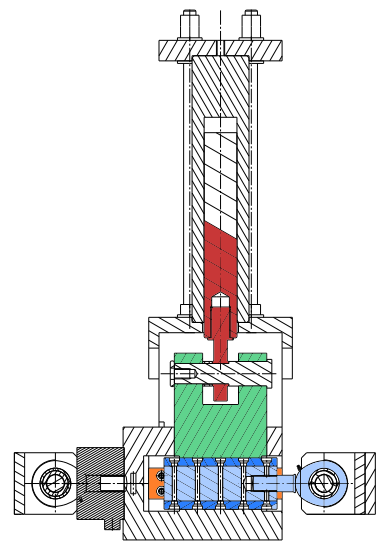

(b)

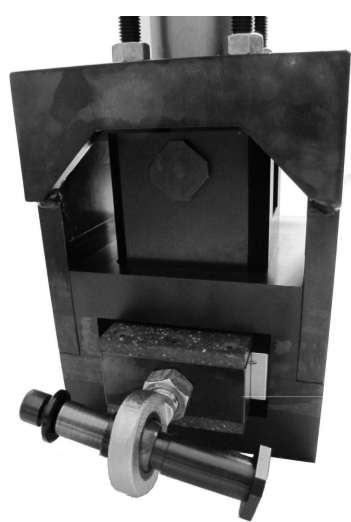

(d)

Fig. 4: Friction damper prototype: (a) schematic diagram of principle (F: force sensor; p:pressure gauge); (b) cross-section view; (c) isometric view; and, (d) photography

small compared to the $800 \mathrm{~kg}$ of the engine it is attached to. Without its jack and ball joints, the friction damper dimensions are $160 \mathrm{~mm} \times 160 \mathrm{~mm} \times 210 \mathrm{~mm}$.

The friction damper is equipped with a $20 \mathrm{kN}$ strain gauge-force sensor which measures the tangential force; in this paper, the term sliding force is employed. A manometer connected to the jack allows to deduce the normal force from the hydraulic pressure $p$. A temperature probe is stuck on the frame of the damper near the friction interface to monitor the heating caused by friction (hidden behind the ball joint on Figure 4d).

\subsection{Prototype testing}

The friction damper is first characterised alone with a Schenck Hydropuls hydraulic jack of $63 \mathrm{kN}$ nominal force to explore the influence of the following parameters: normal force $F_{n}$; temperature; relative displacement amplitude $u_{0}$; and motion frequency $f$. All these parameters could have an influence on the behaviour of the brake lining and therefore on the global behaviour of the friction damper.

The experimental curves are identified with a model of a spring in series with a friction element (see Figure 5). For each single test, the following data are recorded:

- $p$ the pressure in the hydraulic jack;

- $f$ the frequency of the excitation; 


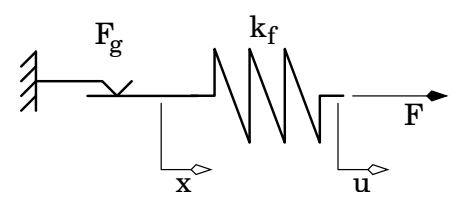

(a)

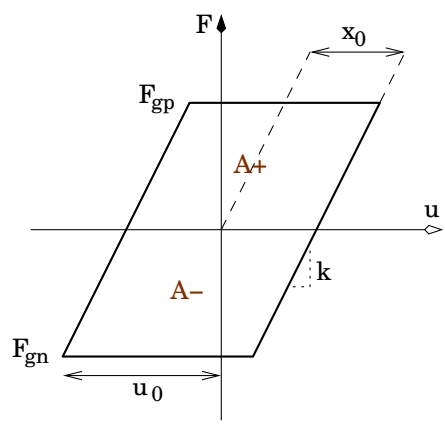

(b)

Fig. 5: Friction damper model: (a) rheological model; and, (b) force-displacement $F$ - $u$ characteristic curve

- $F(t)$ the sliding force in the damper;

$-u(t)$ the imposed displacement of the excitation jack piston.

The data extracted from the force-displacement plot $(F(t)$ versus $u(t)$, see Figure $5 \mathrm{~b})$ are:

- $A$ the total area of the curve;

$-A+$ the area of the curve above $F=0$;

$-A-$ the area of the curve below $F=0$.

The data calculated from the previous physical quantities are:

- $u_{0}$ the amplitude of the imposed displacement (deduced from $u(t)$ );

$-F_{n}$ the normal force in the damper (deduced from $p$ and the piston section, the gain is $\left.125.6 \mathrm{~N} \mathrm{bar}^{-1}\right)$;

- $F_{g p}$ the positive sliding force (deduced from $A+$ and the width of the $F-u$ curve for $F=0$ );

$-F_{g n}$ the negative sliding force (deduced from $A$ - and the width of the $F-u$ curve for $F=0$ ).

The apparent friction coefficient is deduced form the total area $A=2 x_{0} \times 2(2 \mu) F_{n}$ of the curve

$$
A=2\left(u_{0}-\frac{2 \mu F_{n}}{k_{f}}\right) \times 2(2 \mu) F_{n}
$$

where the damper stiffness $k_{f}$ is identified by superimposing all the $\mathrm{u}-\mathrm{F}$ curves on the same plot.

The damper is tested with the following parameters:

- excitation frequencies $f$ between $2 \mathrm{~Hz}$ and $20 \mathrm{~Hz}$;

- imposed displacement $u_{0}$ between $2 \mathrm{~mm}$ and $10 \mathrm{~mm}$;

- pressure $p$ between 50 bar and 210 bar.

A total of 105 individual tests is made. They all proved to be stationary: the extracted data are therefore taken as the mean value on at least 5 periods of the temporal recordings.

\subsection{Tests results}

During the tests, the temperature stayed between $20^{\circ} \mathrm{C}$ and $80^{\circ} \mathrm{C}$ and no particular change in behaviour was noted; this is in fact a very limited temperature range compared to the brake lining maximum admissible temperature of $300{ }^{\circ} \mathrm{C}$ given by the manufacturer of the brake lining. No temperature dependence is therefore considered.

The characteristic curves for all the 105 tests are gathered on Figure 6. Note that only one period of each test is displayed since the tests proved to be stationary and the curves superimpose nicely. The shape of the curves is close to that of the model it is identified with (see Figure 5b), only a few tests show a more oscillatory sliding phase. Near $F=0$, a small jump is visible on every curve: this is the $0.15 \mathrm{~mm}$ cumulative clearance of both ball joints. This 


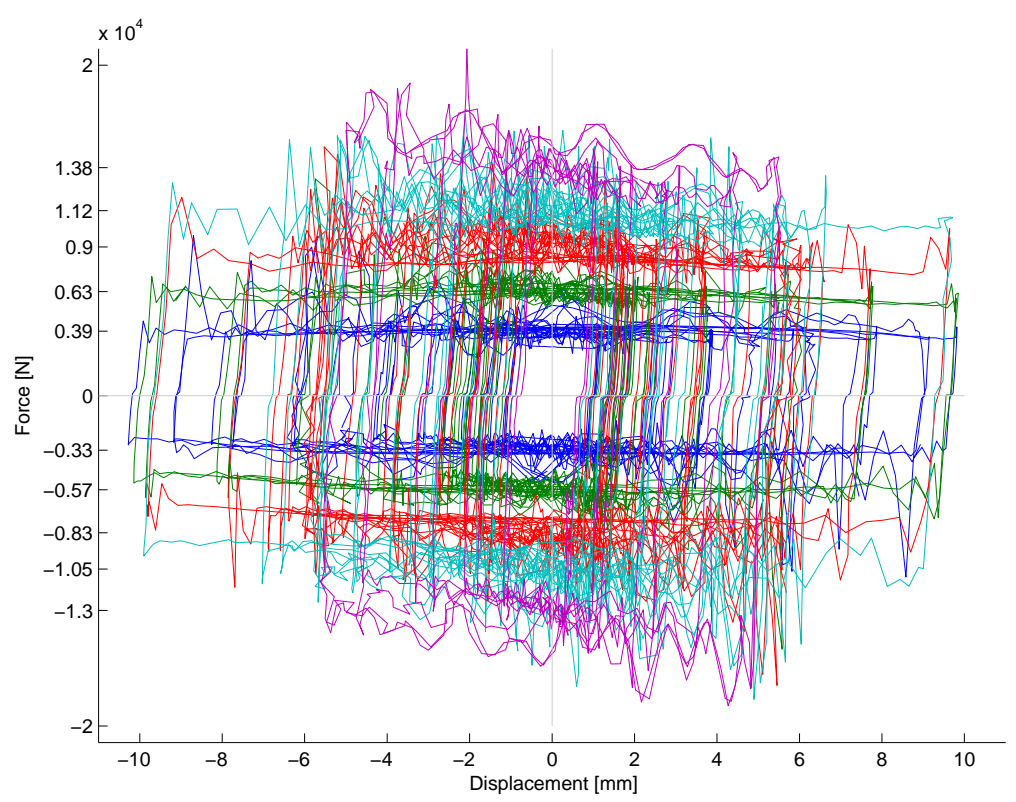

Fig. 6: Force-displacement curves of all the 105 tests. Colours are related to the normal pressure $p$

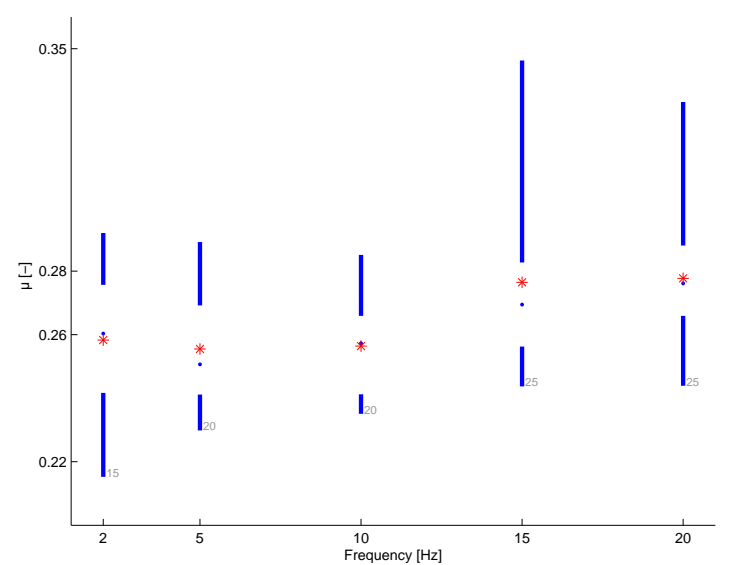

(a)

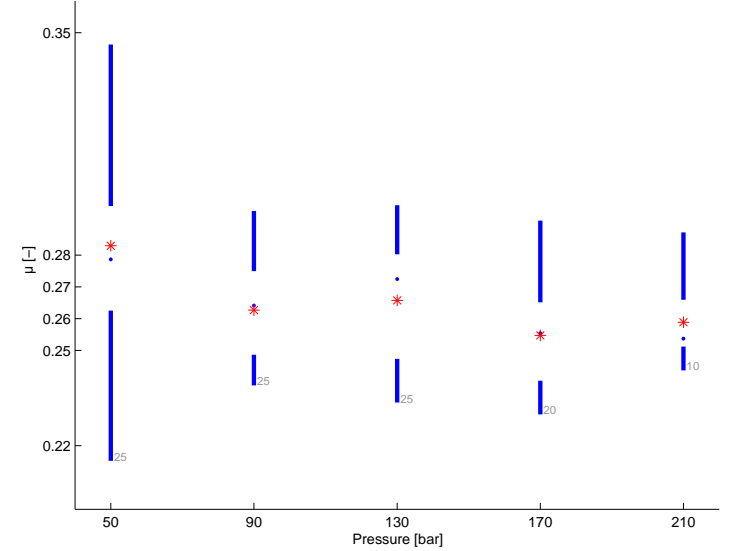

(b)

Fig. 7: Friction coefficient: (a) as function of the frequency and for various normal loads; and, (b) as function of the normal load and for various frequencies

clearance does not affect the way data are extracted from the experimental curves. Finally, all the sticking phases have the same slope of $3.75 \times 10^{7} \mathrm{~N} \mathrm{~m}^{-1}$ which correspond to the damper stiffness $k_{f}$.

The influence of the excitation frequency $f$ and the normal force $F_{n}$ on the friction coefficient $\mu$ is given by Figures $7 \mathrm{a}$ and $7 \mathrm{~b}$. These plots make use of box plots: the quartiles are given by the blue lines, the median is the blue point and the mean value is the red star; the number of experimental points used to make each box plot is given in grey at the bottom of the box.

The mean value of the friction coefficient $\mu$ remains inside the scattering of the points for varying frequency (Figure 7a) or varying normal force (Figure 7b) and no clear tendency is visible. The friction coefficient is thus considered to be independent of the frequency and of the applied normal load. The behaviour of the friction damper is therefore considered to be only dependant on the normal force. 


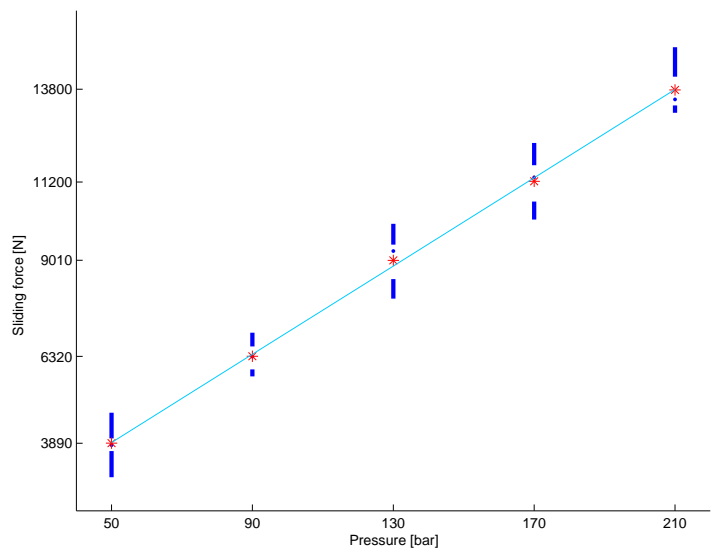

(a)

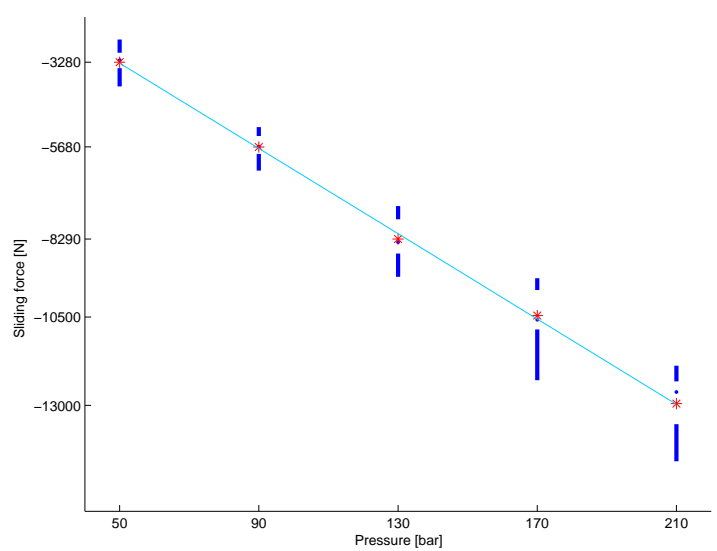

(b)

Fig. 8: Sliding force as function of the hydraulic pressure: (a) positive sliding force $F_{g p}$; and, (b) negative sliding force $F_{g n}$

Figure 8 gives the sliding force with respect to the applied jack pressure $p$; the line correspond to a linear regression performed on all the points. The linear regression fits the points closely: the apparent friction coefficient $\mu$ is independent of the contact pressure on the lining and is given by the slope of the regressions. More precisely, the slope gives the value of $2 \mu$ since there are two friction interfaces - one on each side of the slider- in the path of normal efforts. The mean value is $2 \mu=0.49$.

Before testing the friction damper in the stage scale model in Section 5, temporal simulations on a mechanical system with dry friction are introduced in the next section. This will then enable us to compare the observed experimental behaviour of the friction damper with that of the retained model (spring and dry friction elements in series).

\section{Friction damper modeling}

4.1 Dry friction modeling

The behaviour of the friction damper is inherently non-linear. The force of the friction damper (see Figure 5a) may be written as

$$
F_{N L}= \begin{cases}-k_{f}(u(t)-x(t)) & \text { if } k_{f}|u(t)-x(t)|<F_{g} \\ -F_{g} \operatorname{sign}(\dot{x}) & \text { if } k_{f}|u(t)-x(t)| \geq F_{g}\end{cases}
$$

This equation is used in a numerical integration scheme - using Matlab solver ode15s - to get the behaviour of a mechanical system with a friction damper. The friction force is predicted at time $t_{i}$ and computed by assuming a sticking state $x\left(t_{i}\right)=x\left(t_{i-1}\right)$

$$
F_{N L}^{\text {pred }}=-k_{f}\left(u\left(t_{i}\right)-x\left(t_{i-1}\right)\right)
$$

Since $F_{N L}^{\text {pred }}$ is a prediction of the friction force, its absolute value can be greater than $F_{g}$, hence the $\geq \operatorname{sign}$ in Equation 8. The Coulomb friction law is then used to correct the friction force [11]

$$
F_{N L}\left(t_{i}\right)= \begin{cases}F_{N L}^{\text {pred }} & \text { if }\left|F_{N L}^{\text {pred }}\right|<F_{g} \\ F_{g} \frac{F_{N L}^{\text {pred }}}{\left|F_{N L}^{\text {pred }}\right|} \text { if } & \left|F_{N L}^{\text {pred }}\right| \geq F_{g}\end{cases}
$$

and the internal displacement

$$
x\left(t_{i}\right)=u\left(t_{i}\right)+\frac{F_{N L}\left(t_{i}\right)}{k_{f}}
$$

This is a stiff problem because of the friction forces, Matlab solver ode15s is therefore preferred over the classical ode45 solver. 


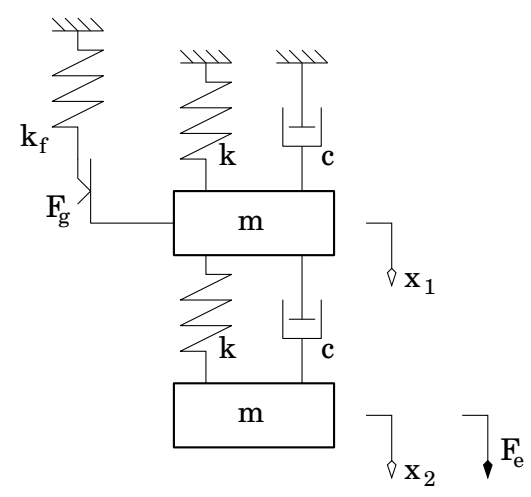

Fig. 9: Mechanical system with friction damper

\subsection{Simulation results}

This numerical scheme is used to compute the behaviour of the two degree of freedom mechanical system depicted in Figure 9. The system is damped with a friction damper taking advantage of the relative displacement between mass 1 and the ground and the force excitation is applied on mass 2. This configuration is close to that of the scale model test: the friction damper prototype takes advantage of the relative displacement between the engine mass and the outer shell and the excitation is applied on another part of the stage scale model.

The following parameters are used: $m=1 \mathrm{~kg} ; k=10 \mathrm{~N} \mathrm{~m}^{-1} ; c=0.1 \mathrm{~N} \mathrm{~s} \mathrm{~m}^{-1} ; k_{f}=10 \mathrm{~N} \mathrm{~m}^{-1}$; $F_{g}=25 \mathrm{~N}$ to $3000 \mathrm{~N}$; and $F_{e}=100 \mathrm{~N}$. The amplitude of the response of mass 1 is given by Figure 10a. This Figure only displays the first resonance of the system, the response curves are typical of a mechanical system with dry friction.

Figure 10a illustrates the two limiting cases of $F_{g}=0$ and $F_{g}=\infty$. For low sliding force $F_{g}$, the stiffness of the friction damper $k_{f}$ is not active since the damper is nearly always sliding; for $F_{g}=0$ the eigenfrequency is therefore that of the unmodified system (ie. the system without the friction damper) and is $1.95 \mathrm{rad} \mathrm{s}^{-1}$. On the contrary, for high sliding force $F_{g}$, the stiffness of the friction damper $k_{f}$ acts fully parallel to the stiffness $k$ since the damper is nearly always stuck; for $F_{g}=\infty$ the eigenfrequency is therefore that of the system modified by the addition of a stiffness $k_{f}$ between the ground and the first mass, yielding a higher eigenfrequency of $2.42 \mathrm{rad} \mathrm{s}^{-1}$.

Figure 10c gives the ratio of sliding time to oscillation period $\tau$ - defined as the portion of time for which the damper is in sliding state, ie. $\left|F_{N L}\right|=F_{g}$ - as function of the frequency. Note that the curves can appear noisy but this is only an artifact due to the temporal discretisation of the force signal whose time step is automatically chosen by the ODE solver and may vary on one period of the force signal. As the sliding force increases, the ratio of sliding time logically decreases since the amplitude of the excitation force is kept constant. For a given curve, the ratio of sliding time is maximum for the resonance frequency (defined here as the frequency for which the amplitude is maximum).

One could expect that the maximum damping of the vibration mode (defined as the greatest reduction of the resonance amplitude) corresponds to the maximum dissipated energy in the friction damper. This is however not the case here for the studied simple mechanical system (see Figure 10b). Other mechanical systems were therefore considered to see if a tendency could be established. Yet no clear relationship between the dissipated energy and the maximum damping could be established; the shape of the dissipated energy curves really depends on the mechanical system and, for a given system, on the observed mode.

Al Sayed et al. [1] observed that the maximum damping occurred for a ratio of sliding time of $50 \%$ for a one degree of freedom system. This may only be valid for one degree of freedom. Indeed this is no longer true here, the lowest resonance occurs for a ratio of sliding of 0.65 (see Figure 10d), and this was confirmed on the other studied systems. What could be called the optimum ratio of sliding thus depends on the mechanical system.

The friction damper was individually tested in Section 3; simulation tools were introduced in the present Section to model the behaviour of the friction damper. The friction damper is 


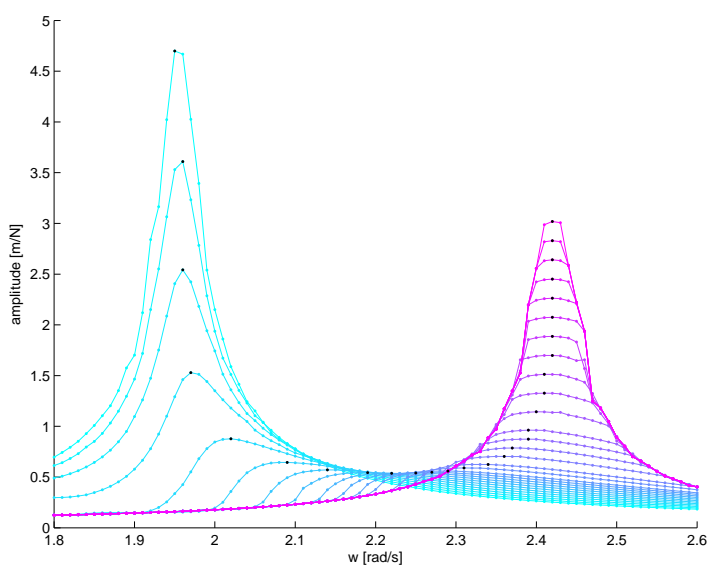

(a)

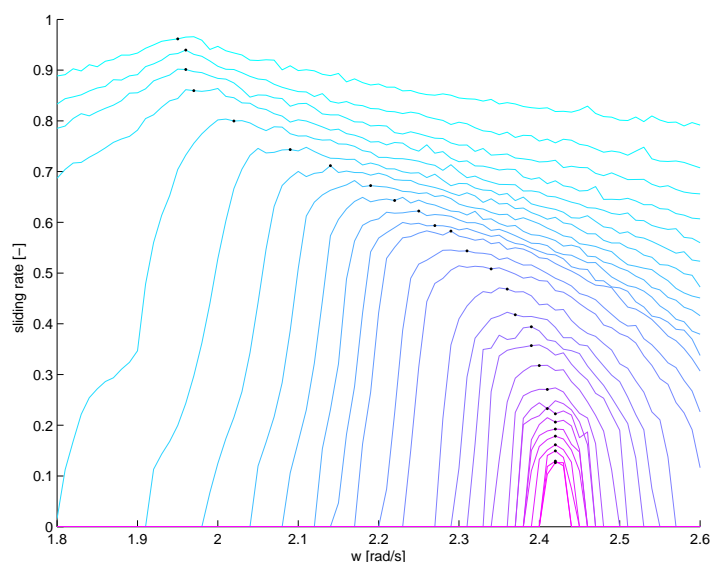

(c)

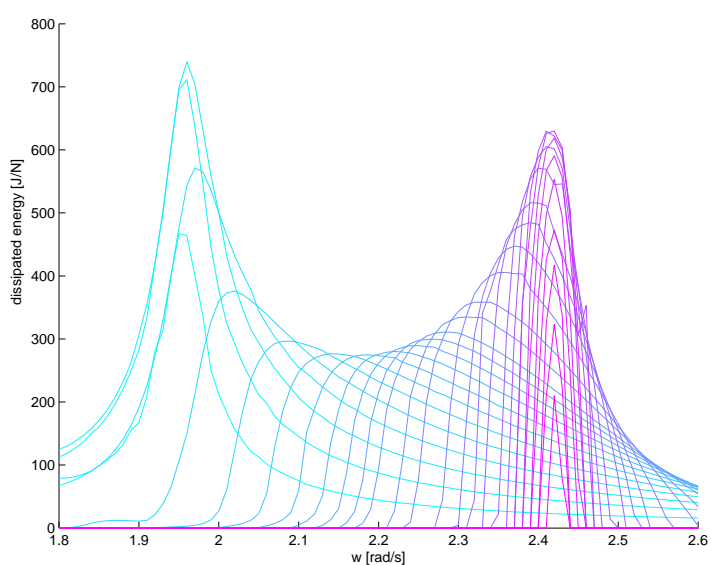

(b)

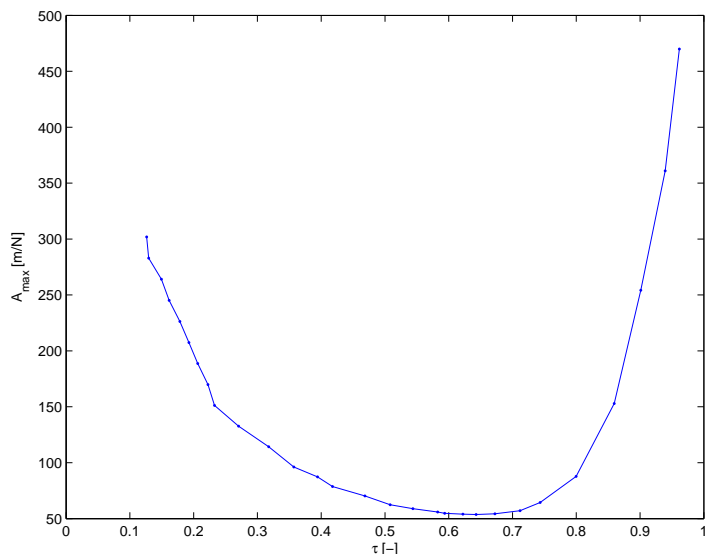

(d)

Fig. 10: Numerical simulation of the friction damper: (a) amplitude response of mass 1; (b) dissipated energy in the friction damper on one period; (c) ratio of sliding time to oscillation period; and, (d) resonance amplitude as function of the ratio of sliding. Sliding force $F_{g}$ varying from $25 \mathrm{~N}$ to $3000 \mathrm{~N}$.

now tested in the stage scale model in order to assess its ability to reduce the vibration levels transmitted to the payload; the experimental behaviour will be compared to the simulations to evaluate the relevance of the model used for the friction damper.

The simulations use a force excitation term; on the other side, the experimental setup is excited by its base by a hydraulic jack whose displacement is controlled. It will be shown later that despite this difference, both systems equipped with a friction damper (the experimental and the numerical system) exhibit the same behaviour. The numerical study of a displacement excited system with a friction damper is hard to achieve; indeed the displacement excitation causes a retroaction in the dynamic equation, and this retroaction is made non-linear by the friction term. Treating all this in a numerical integration scheme is quite complex and is far beyond the objective of this study. 


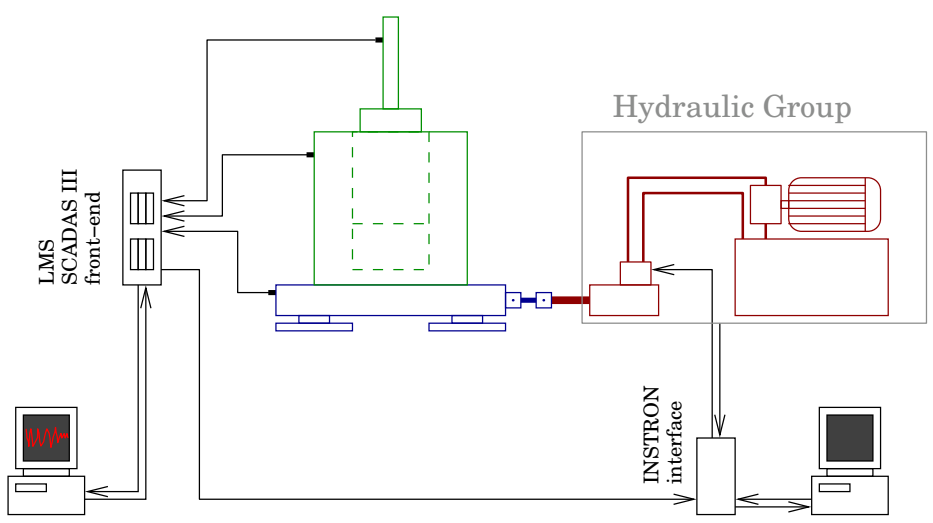

Test control \& acquisition

Hydraulic control

Fig. 11: Experimental setup for the test of the scale model

\section{Damping of the space launcher stage model}

\subsection{Space launcher stage model testing}

The friction damper is installed inside the scale model; it is clamped on one side to the reinforcement belt inside the outer shell and on the other side to the groove of the engine ballast (see Figure 1a).

The scale model is excited through a stiff shaking table which weights $650 \mathrm{~kg}$ (see Figure 1c). The shaking table is guided by four ball bearing slide and driven by a $160 \mathrm{kN}$ nominal forcehydraulic jack (Schenck Hydropuls); this jack is piloted by three Moog $631 \mathrm{~min}^{-1}$ servovalves.

The frequency response functions are obtained by swept sine testing of the stage with the shaking table. The scale model is equipped with 14 accelerometers that measure the response in the direction of the excitation and also in the horizontal transverse direction. The experimental setup is given by Figure 11 .

The scale model is first shaken without the friction damper to get its initial behaviour. The first two modes are the flexion mode of the payload on its support and the flexion mode of the engine, respectively at $15.5 \mathrm{~Hz}$ and $18.7 \mathrm{~Hz}$.

\subsection{Damping tests results}

The frequency response of the stage scale model equipped with the friction damper is given by Figure 12. The pressure $p$ varies from 20 bar to 120 bar by increments of 10 bar; this corresponds to a normal force of respectively $2.51 \mathrm{kN}$ to $15.1 \mathrm{kN}$ with a $1.256 \mathrm{kN}$ step. The grey curve is the response of the structure without the friction damper.

The resonance of the first mode is noisy because the excitation level is lowered to stay within the design domain and not damage the stage. This design domain allows acceleration levels up to $6 \mathrm{~g}$ on the payload and $3 \mathrm{~g}$ on the engine, both laterally, with a safety factor of 1.5. Outside this noisy frequency zone, the excitation level of the shaking table is $1 \mathrm{~g}$.

A down-swept sine test is performed on the structure equipped with the damper to check that there is no major difference compared to the up-swept sine test presented here.

\subsubsection{Behaviour of the stage with friction damper}

The friction damper only influences the second mode of the stage which is the engine flexion mode. Indeed, the first mode is the flexion mode of the payload and the relative displacement between the outer shell and the engine is very limited for this mode; that is why the response of the first mode is not shown here. On the contrary, when the normal loading of the friction damper increases, the resonance of the second mode is shifted from $18.7 \mathrm{~Hz}$ to $23.0 \mathrm{~Hz}$. Note that even for the small pressure $p=20$ bar in the friction damper jack, the engine vibration 

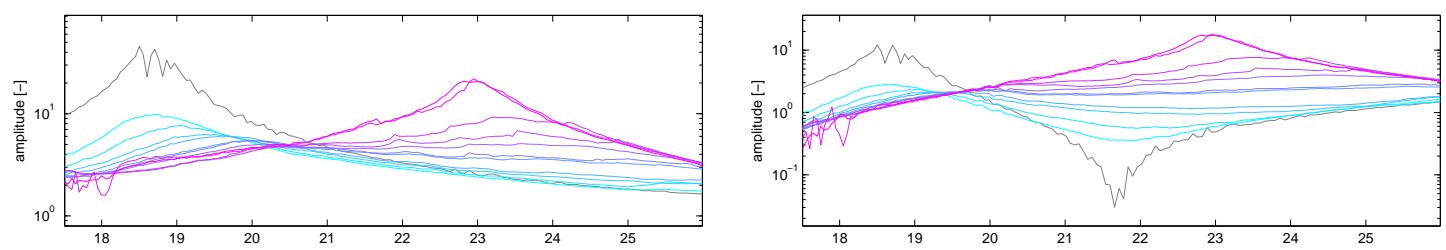

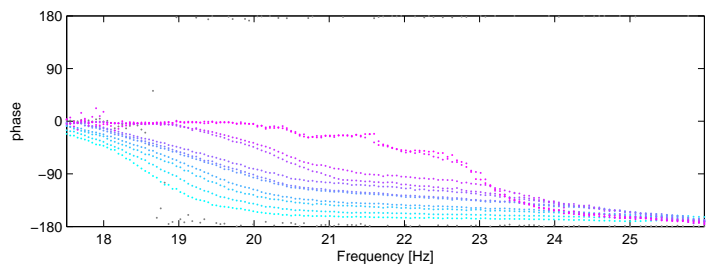

(a)

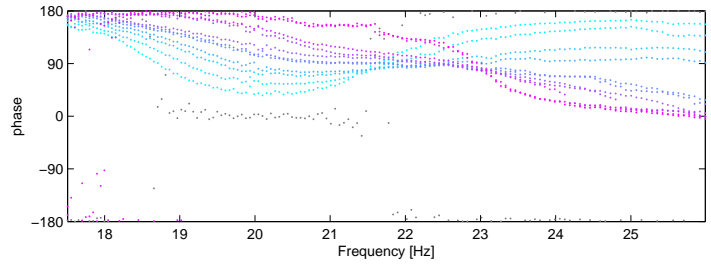

(b)

Fig. 12: Influence of the normal loading on the response of the launcher (20 bar to 120 bar by 10 bar steps): (a) response at the bottom of the engine (B1); et, (b) response at the bottom of the payload (L1)

amplitudes are reduced by a factor of 4 (see Figure 12a). With increasing pressure, the frequency of the maximum of amplitude for the second mode progressively increases and finally tends toward $23.0 \mathrm{~Hz}$; the maximum of vibration amplitude decreases for pressures up to 80 bar and then it increases again. Indeed, it can be seen on the temporal force signal (an extract is given in Figure 13) that no slip occur which means that no energy is dissipated and that only the stiffness of the friction damper acts on the structure: the frequency is shifted and the modal damping is low.

These tests illustrate the typical behaviour of a structure with friction damping. We can also infer from these tests that the friction damper model - a spring in series with a friction element - is appropriate for the damper prototype.

\subsubsection{Damper force}

Figure 13 gives the force signal $F(t)$ given by the force sensor of the friction damper; the grey lines are the sliding forces determined during the friction damper characterisation (see Section 3 and Figure 8). Figure 13 gathers all the states the friction damper can encounter: from $p=20$ bar to 80 bar the damper is sliding at different ratios of sliding time; at $p=90$ bar the ratio of sliding time is very close to zero; and above $p=100$ bar the damper slider is stuck and the force remains below the sliding force, the signal is no more a trapezoid but sinusoid. For the smallest pressures (20 bar and $30 \mathrm{bar}$ ) and on the $18 \mathrm{~Hz}$ to $26 \mathrm{~Hz}$ frequency range, the slider slides at a force visibly inferior to the force determined during the characterisation. We will see later that this may impact the ratio of sliding.

\subsubsection{Ratio of sliding time}

The ratio of sliding is defined as the portion of time the friction damper is in a sliding state. It is determined from the force signal. It is however difficult to compute since the force signal is perturbed by the shocks due to the small clearance in the two ball joints of the damper (see Figure 13). The ratio of sliding is therefore estimated with the area $A_{\text {trap }}$ of the absolute value of the force signal $F(t)$ on six periods (see Figure 14) through equation

$$
A_{\text {trap }}=T \tau F_{g}+T(1-\tau) \frac{1}{2} F_{g}
$$

which is based on the assumption that the signal has a trapezoid shape. The ratio of sliding is thus

$$
\tau=\frac{2 A_{\text {trap }}}{T F_{g}}-1
$$



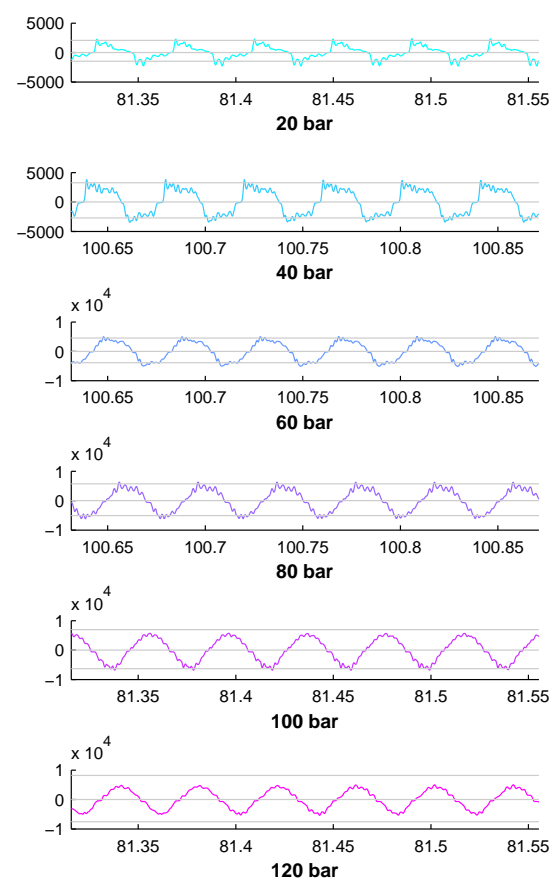

Fig. 13: Force signal at $25 \mathrm{~Hz}$ for each pressure $p$ in the friction damper

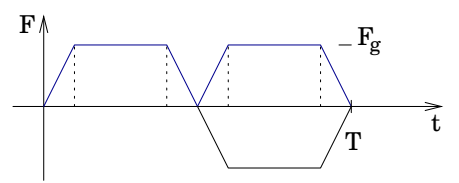

Fig. 14: Trapezoid signal (-) and absolute value of the trapezoid signal (一)

The sliding force $F_{g}$ is taken as $2 \mu \times F_{n}$ (or $0.5 \times 125.6 \times p$ ), this corresponds to the characterisation of the friction damper (see Section 3.3). When no sliding occur, the ratio of sliding is found as negative with Equation 13 since the amplitude of the force signal is smaller than the sliding force and the measured area of the signal is consequently small too. In this case, the ratio of sliding $\tau$ is replaced by 0 .

The ratio of sliding time in the friction damper is given in Figure 15. The ratio of sliding curve for each test is dome-shaped and goes through a maximum. The four first test (20 bar to 50 bar) deviate from this trend and are more noisy; this can be explained by the fact that the sliding force is inferior to the characterised sliding force, leading to an underestimation of the ratio of sliding. That is why the experimental curves in Figure 15 do not seem to be organized the same way as the simulated curves in Figure 10c. However, as in the simulations, the maximum ratio of sliding shifts to the right for increasing pressures $p$ and ratios of sliding tend to diminish for pressures going from 60 bar to 120 bar.

\subsubsection{Dissipated energy in the friction damper}

The amplitude of the relative displacement of the attachment points of the friction damper is illustrated by Figure 16. As the sliding force increases with increasing pressure $p$, the amplitude of the relative displacement decreases. Below $0.15 \mathrm{~mm}$, the relative displacement $u_{0}$ is taken up by the clearance in the ball joints of the friction damper.

Figure 17 gives the dissipated energy in the friction damper. It is computed with the relative displacement between the damper attachment points and the force in the friction damper (area under the $\mathrm{u}-\mathrm{F}$ curve). The maximum damping is obtained with pressure $p=80 \mathrm{bar}$, this is also the pressure for which the dissipated energy is maximum near the resonance. However, this 


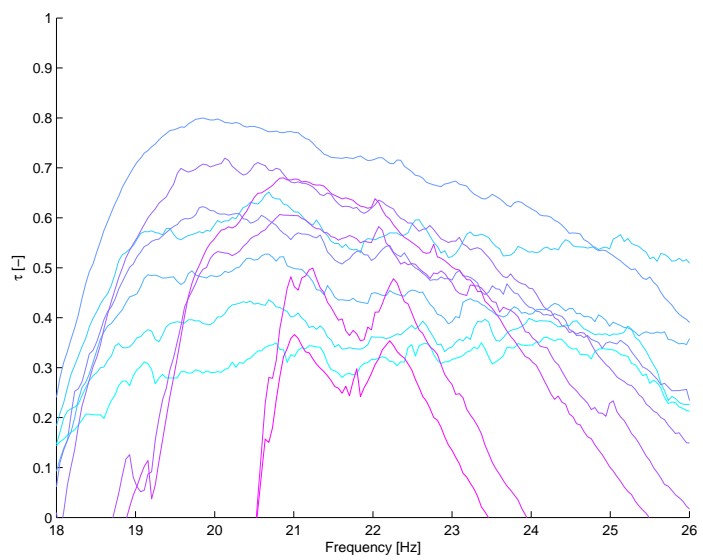

Fig. 15: Ratio of sliding time to oscillation period in the friction damper as function of the frequency

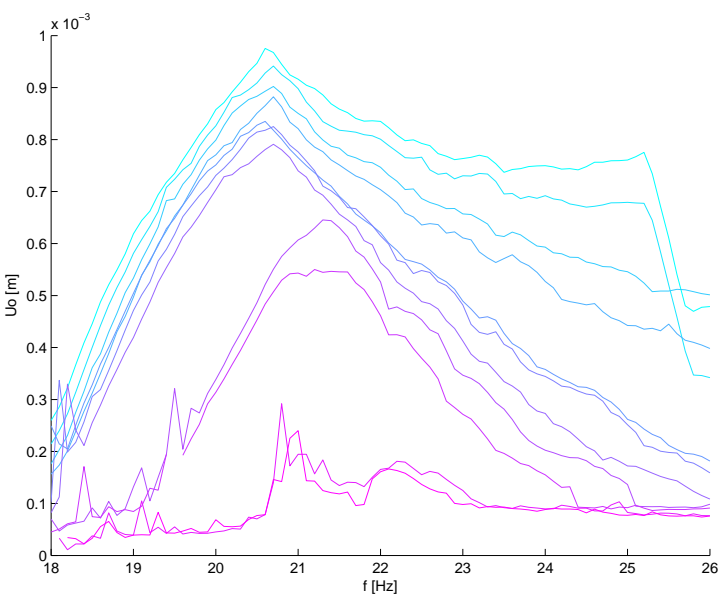

Fig. 16: Relative displacement of the attachment points of the friction damper

may only be a coincidence since it was shown previously in Section 4.2 that this is not always the case.

For the two highest pressures $p$ of 110 bar and 120 bar, the ratio of sliding is very low and the slider remains mostly stuck: the dissipated energy in the friction damper is low and the resonance is just shifted by the damper stiffness but not attenuated. On the other side, for the lowest pressures $p$ of 20 bar and 30 bar, le friction damper is always in slipping state but the sliding force is low, that is why the dissipated energy is also limited.

\subsubsection{Ratio of sliding time and maximum amplitude}

The maximum amplitude $A_{\text {max }}$ for each test is plotted as function of the ratio of sliding at this frequency (see Figure 18). With increasing ratio of sliding, the maximum amplitude decreases. Some more points with higher rates would be necessary to check if the curve goes through a minimum as in the simulation of Section 4.2 or as was demonstrated by Al Sayed et al. [1]. The experimental curve and the simulated curve show however the same tendency for the low to middle ratios of sliding. The unavoidable existence of clearance in the ball joints may be the cause of the limited measured ratios of sliding during the tests. 


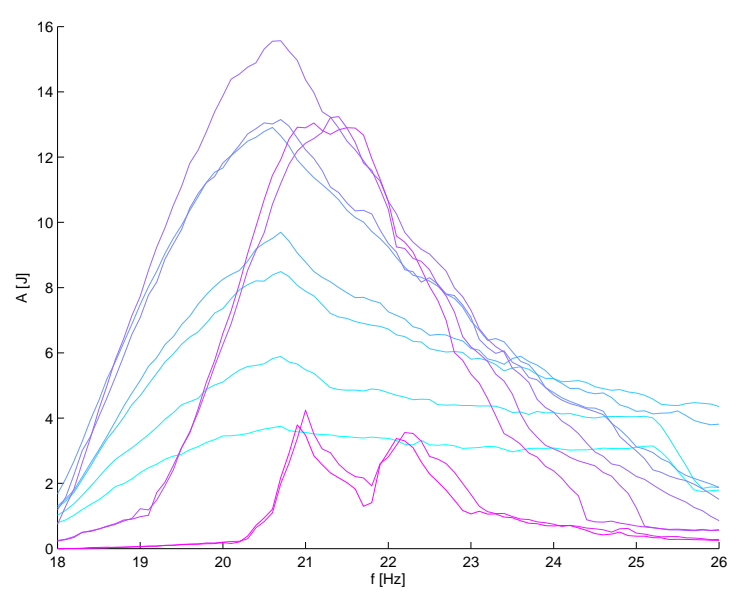

Fig. 17: Dissipated energy in the friction damper

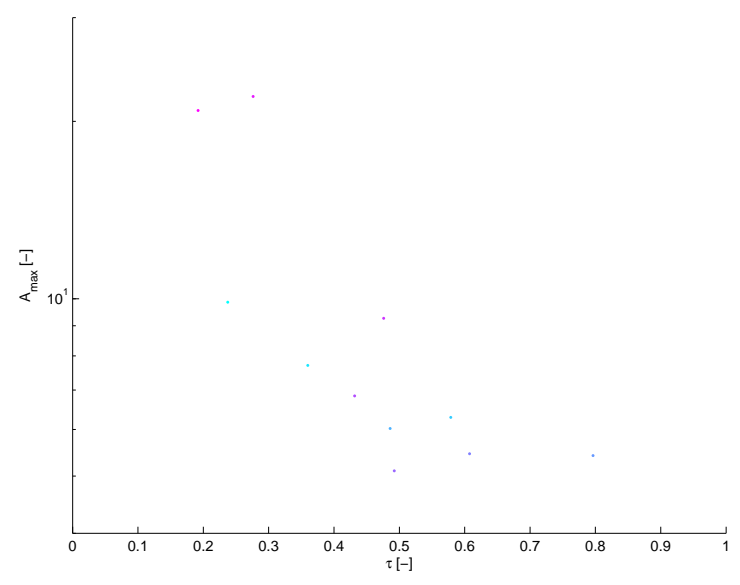

Fig. 18: Amplitude maximum as function of the ratio of sliding

5.3 Validity of the design based on the dissipated energy

In this section, the validity of the approach developed in Section 2.2 is assessed in light of the experimental tests. The maximum amplitude of the relative displacement $u_{0}$ between the attachment points of the friction damper for the optimum pressure of 80 bar is $0.78 \mathrm{~mm}$. The clearance of $0.15 \mathrm{~mm}$ in the ball joints may be withdrawn: the amplitude of relative displacement at the friction interface inside the friction damper is therefore $0.63 \mathrm{~mm}$, which gives a theoretical optimal sliding force of $11.8 \mathrm{kN}$ when using the actual stiffness of the damper in Equation 3.

The best damping of the scale model was achieved for a pressure in the damper of 80 bar: this corresponds to a normal force $F_{n}$ of $10.0 \mathrm{kN}$ and an experimental optimal sliding force of $5.0 \mathrm{kN}$.

The design method that was used therefore gave the correct order of magnitude for the estimation of the sliding force. The result proves to be quite satisfactory, considering that this is a quick design method. Anyway, experimental tests are always needed to evaluate the real performances of the devices.

\section{Conclusion}

In this study, a friction device for damping space launcher vibrations is designed and a prototype is built. The friction damper is first characterised alone and its behaviour is described by a spring in series with a friction element. The friction damper is then mounted inside a scale 
model of a launcher last stage; this scale model was made for the occasion. The tests show that the friction damper provides an efficient mean of reducing vibration levels, provided that the sliding force is correctly set. The adaptive friction damper prototype enables to adjust the sliding force by controlling the normal force. If the sliding force is too important with regard to the force passing through the damper, it will not dissipate energy since no sliding occur; on the contrary, if the sliding force is too small, the friction damping will not be optimal.

The vibration levels at the base of the payload are reduced, thanks to the use of the friction damper prototype, by a factor of 15 . Indeed, the vibrations of engine mass are reduced by a factor of 8 . The simple design method, based on the equivalence between friction energy dissipation and viscous energy dissipation, is used to dimension the friction damper prototype and provides an estimation of the necessary sliding force.

Future work will concentrate on the technologies to make the friction damper semi-active and on the modelling of the behaviour of a large structure equipped with a passive or semiactive friction damper.

\section{References}

1. Al Sayed B, Chatelet E, Baguet S, Jacquet-Richardet G (2011) Dissipated energy and boundary condition effects associated to dry friction on the dynamics of vibrating structures. Mechanism and Machine Theory 46(4):479-491, DOI 10.1016/j.mechmachtheory.2010.11.014, URL http://www.sciencedirect.com/science/article/pii/S0094114X10002119 10, 15

2. Brizard D, Besset S, Jézéquel L, Troclet B (2012) Determinantal method for locally modified structures. application to the vibration damping of a space launcher. Computational Mechanics pp 1-14, DOI 10.1007/s00466-012-0695-9, URL http://www.springerlink. com.gate6. inist.fr/content/5k41075228kr6x44/abstract/ 2, 3

3. Courtney-Pratt JS, Eisner E (1957) The effect of a tangential force on the contact of metallic bodies. Proceedings of the Royal Society of London Series A Mathematical and Physical Sciences 238(1215):529-550, DOI 10.1098/rspa.1957.0016, URL http://rspa.royalsocietypublishing.org/content/238/1215/529 2

4. Golafshani A, Gholizad A (2009) Friction damper for vibration control in offshore steel jacket platforms. Journal of Constructional Steel Research 65(1):180-187, DOI 10.1016/j.jcsr.2008.07.008, URL http://www.sciencedirect.com/science/article/pii/S0143974X08001727 3

5. Guglielmino E, Edge KA (2004) A controlled friction damper for vehicle applications. Control Engineering Practice 12(4):431-443, DOI 10.1016/S0967-0661(03)00119-9, URL http://www.sciencedirect.com/science/article/pii/S09670661030011993

6. Guglielmino E, Sireteanu T, Stammers CW, Gheorghe G, Giuclea M (2008) Friction dampers. In: Semi-active Suspension Control, Springer London, pp 99-163, URL http://www. springerlink. com.gate6.inist.fr/content/l66g38305h3u5640/abstract/ 3

7. Hinrichs N, Oestreich M, Popp K (1998) On the modelling of friction oscillators. Journal of Sound and Vibration 216(3):435-459, DOI 10.1006/jsvi.1998.1736, URL http://www.sciencedirect.com/science/article/pii/S0022460X989173692

8. Ibrahim RA (1994) Friction-induced vibration, chatter, squeal, and Chaos-Part i: Mechanics of contact and friction. Applied Mechanics Reviews 47(7):209, DOI 10.1115/1.3111079, URL http://link. aip.org/link/AMREAD/v47/i7/p209/s1\&Agg=doi 2

9. Ibrahim RA (1994) Friction-induced vibration, chatter, squeal, and Chaos-Part II: dynamics and modeling. Applied Mechanics Reviews 47(7):227, DOI 10.1115/1.3111080, URL http://link.aip.org/link/AMREAD/v47/i7/p227/s1\&Agg=doi 2

10. Kim J, Choi H, Min K (2011) Use of rotational friction dampers to enhance seismic and progressive collapse resisting capacity of structures. The Structural Design of Tall and Special Buildings 20(4):515-537, DOI 10.1002/tal.563, URL http://onlinelibrary.wiley.com/doi/10.1002/tal.563/abstract; jsessionid=43B58DC92AC3F26D69FC6A603215E8A8.d02t02 3

11. Laxalde D, Thouverez F, Sinou J, Lombard J (2007) Qualitative analysis of forced response of blisks with friction ring dampers. European Journal of Mechanics - A/Solids 26(4):676-687, DOI 10.1016/j.euromechsol.2006.10.002, URL http://www.sciencedirect.com/science/article/pii/S09977538060011369

12. Mirtaheri M, Zandi AP, Samadi SS, Samani HR (2011) Numerical and experimental study of hysteretic behavior of cylindrical friction dampers. Engineering Structures 33(12):3647-3656, DOI 10.1016/j.engstruct.2011.07.029, URL http://www.sciencedirect.com/science/article/pii/S0141029611003130 3

13. Mualla IH, Belev B (2002) Performance of steel frames with a new friction damper device under earthquake excitation. Engineering Structures 24(3):365-371, DOI 10.1016/S0141-0296(01)00102-X, URL http://www.sciencedirect.com/science/article/pii/S014102960100102X 2

14. Rittweger A, Albus J, Hornung E, Öry H, Mourey P (2002) Passive damping devices for aerospace structures. Acta Astronautica 50(10):597-608, DOI 10.1016/S0094-5765(01)00220-X, URL http://www.sciencedirect.com/science/article/B6V1N-44TV6SP-3/2/e3b00ba0563b085408c247a18a965c43 
15. Romeuf T, Le Gallo V (2005) ARIANE 5 new upper composite including a non linear damper. prediction of the dynamic behaviour during On-Ground tests and flights. Moscow 2 